\title{
NOTE
}

\section{CARBON TAXATION VERSUS EMISSIONS TRADING SCHEMES?}

\section{JOHN SHEEHAN*}

\section{INTRODUCTION}

Given that Australia is now internationally obliged to reduce national Greenhouse Gas (GHG) emissions, ${ }^{1}$ the manner of decarbonisation of the atmosphere is of crucial importance. One way of reducing GHG emissions is to introduce a carbon tax whereby a tax of $\$ \mathrm{X}$ per tonne of carbon is imposed on industries emitting carbon dioxide. Another approach is to introduce a scheme - known as an Emissions Trading Scheme (ETSs) - which allows trading of permits to emit GHGs.

\section{Practicalities of a Carbon Tax System}

The principle on which a carbon tax system operates is that the cost of producing goods and services which are emissions-intensive increases due to the carbon tax, and hence the consumption of those particular goods and

\footnotetext{
* Deputy Director, Asia-Pacific Centre for Complex Real Property Rights; Adjunct Professor, Faculty of Design Architecture and Building, University of Technology, Sydney;

Past President (NSW Division), and Chair, Carbon Property Rights Committee; Australian Property Institute; Board Member; Spatial Industries Business Association (Australia).

This paper has been prepared by the author primarily with the financial support provided by the NSW Division of the Australian Property Institute, the Australian Spatial Industries Business Association (Australia), and the Asia- Pacific Centre for Complex Real Property Rights, University of Technology, Sydney.

${ }^{1}$ The Kyoto Protocol was adopted by the parties to the United Nations Framework Convention on Climate Climate Change (UNFCCC) on 11 February 1997, and came into force on 16 February 2005. Australia ratified the Protocol on 3 December 2007, thereby incurring commitments to limit or reduce GHG emissions to specific levels in the commitment period (2008-2012), with collective emissions to be reduced by at least 5 per cent from 1990 levels.
} 
services is reduced as they become more expensive. Arguably, a carbon tax encourages industries to produce goods and services which are less emissionsintensive by taking alternative manufacturing pathways. The alteration of manufacturing behaviour is one pathway which avoids raising the price of goods and services significantly.

The carbon tax would arguably continue to increase until evidence existed that a reduction in emissions was occurring and indeed had fallen to the desired level. Economists such as Gittins note that a carbon tax:

... is intended to discourage the consumption of [emissions-intensive] goods and services, while also providing producers with an incentive to find ways of reducing the amount of emissions generated by their production process. $^{2}$

\section{The Canadian Experience of Carbon Taxation}

In British Columbia, some concerns have been expressed over the cost of decarbonisation, following the introduction on 1 July 2008 of a carbon tax scheme. The current Provincial Budget, published on 17 February 2009, lists a carbon tax collection of CA\$300 million for the 2008-2009 fiscal year. For the fiscal year 2009-2010 the carbon tax has been estimated in the Budget at approximately CA $\$ 546$ million, rising to CA \$754 million in 2010-2011 and CA\$968 million in 2011-2012. ${ }^{3}$

When the tax was introduced in 2008 the base rate was CA\$10 per tonne of carbon dioxide. It increased to CA \$15 on 1 July 2009 and is to increase in successive similar amounts annually until it reaches CA\$30 per tonne in 2012. The tax collected is returned under the scheme to individuals and industry in the form of reductions in personal and corporate income tax, together with low income tax credits. ${ }^{4}$ It has been estimated that the projected increases in the carbon tax in 2009-2010 will add CA $\$ 0.0117$ (1.17cents) to the cost of a litre of petrol and CA $\$ 0.0135$ (1.35cents) to the cost of heating oil or diesel. ${ }^{5}$

Despite the concerns that have been expressed, this increase in sensitive fuel costs due to the carbon tax is surprisingly small. However, whether this Canadian carbon tax is actually encouraging decarbonisation is yet to be

\footnotetext{
${ }^{2}$ Ross Gittins, ‘Economists fiddle while climate burns’, The Sydney Morning Herald (Sydney) 14 March 2009, 5.

3 'Long-term Returns, BC's Carbon Tax and ABCP', The Globe and Mail (Toronto), 19 February 2009, B5.

${ }^{4}$ Ibid.

${ }^{5}$ Ibid.
} 
determined. Somewhat confusingly, British Columbia also has a form of ETS or 'cap-and-trade' system, which was introduced on 3 April 2008. ${ }^{6}$ However, whilst offsets gained by reforestation have a potential to be used by carbon intensive industries, the Canadian Government, when signing the Kyoto Protocol, declared that it was the owner of all 'forest carbon sinks', an issue which has created concern amongst First Nations ${ }^{7}$ and the Provincial Government of British Columbia. ${ }^{8}$

\section{EmISSIONS TRADING SchEMES}

The principle on which an ETS operates is that tradable permits are issued by government, allowing the holder to emit a defined amount of GHGs into the atmosphere. Parties can trade permits, allowing the highest economic value for the permit to be achieved. The total number of permits (or cap) is the nation's emissions limit.

Arguably, ETSs represent a more sophisticated pathway to emissionsreduction than do carbon tax systems. However they are almost certainly more difficult to monitor and administer than a carbon tax system, which involves the imposition of a specific tax rate for a specific purpose. Michael Costa, former NSW Treasurer, argues that the Carbon Pollution Reduction Scheme Bill 2009 (CPRS Bill) (the Australian bill intended by the Rudd Labor government to introduce emissions-trading) was too complicated in a country which currently has 'one of the most complex personal tax regimes in the world'. 9

There are also potential problems specific to ETSs, such as market speculation and the verification of climate data.

\section{The Speculative Nature of Carbon Trading}

The insolvency of Lehman Brothers highlights the already speculative nature of ETSs, that company having previously sought to enter the carbon market in the

\footnotetext{
${ }^{6}$ Greenhouse Gas Reduction Targets Act, 2008 (BC).

${ }^{7}$ First Nations Forestry Council (2008) Carbon Credit Opportunities for First Nations in BC. Briefing document for BC Forestry Round Table (Vancouver), 4.

${ }^{8}$ The Provincial Government owns over 90 per cent of all forests in British Columbia personal communication from Chris Rolfe, Chair Climate Action Legal Team, Ministry of Attorney General, (19 February 2009).

${ }^{9}$ Michael Costa, cited in 'Inconvenient Truth of Carbon Policy', The Sunday Telegraph (Sydney), 8 March 2009, 95.
} 
... hope to dominate ... centred on the buying and selling of carbon permits, through the EU's Emissions Trading Scheme (ETS) set up in 2005, the UN's Clean Development Mechanism (DM) and the 'cap and trade' system proposed for the US by both McCain and Obama. ${ }^{10}$

While there is no suggestion that insolvency was caused by the entry into the carbon market, nevertheless the interest that Lehman Brothers had in carbon emissions trading centred on the concept that the number of permits ${ }^{11}$ available would fall each year, resulting in an increasing shortfall in emission capacity. This reduction in permits could only be addressed in two ways, either through active reduction in carbon emissions or through the purchase of further permits, presumably at increasing cost. This aspect was not missed by Lehman Brothers:

Because the [carbon] titles are transferable and because large numbers were allocated to large corporations when the licenses were first introduced [by the EU and UN], there arose a market in carbon-trading. Powerful businesses were able to sell their $\mathrm{CO}_{2}$ permits to smaller companies that needed to emit a certain amount of $\mathrm{CO}_{2}{ }^{12}$

\section{The InAcCuRAcy of Climate Change INFormation}

The issue of overall accuracy of climate change information has also been highlighted by the Australian Competition and Consumer Commission in its findings arising from investigations into claims being made about carbon offsets. There are strict obligations under the Trade Practices Act 1974 (Cth) prohibiting misleading and deceptive conduct, together with a series of prohibitions against specific misrepresentations. ${ }^{13}$ Importantly, the Commission published an Issues Paper in January $2008^{14}$ seeking comments on claims about carbon offsets and whether such claims, when assessed against the requirements of the Commonwealth trade practices legislation, could involve breaches. Claims as to carbon offsets appear to be made by a quite wide range of actors, including manufacturers, entrepreneurs and even airlines, to entice consumers to consider a particular product or service.

${ }^{10}$ Christopher Booker, 'Financial Crisis: Lehman Misses Out on Carbon Credit Scam', The Sunday Telegraph (London), 21 September 2008, 28.

${ }^{11}$ In Australia these are known as AEUs or Australian Emission Units.

12 Brendan O'Neill, 'Al Gore and his allies know the color of money', The American Conservative (online), 1 August 2009, <http://www.amconmag.com/article/ 2009/aug/01/00008/>

${ }^{13}$ See Trade Practices Act 1974 (Cth) ss 52 and 53.

${ }^{14}$ Australian Competition and Consumer Commission, Issues Paper: The Trade Practices Act and Carbon Offset Claims (2008). 
In June 2008 the Commission released subsequent guidelines on carbon claims, recognising the above problem and observing that:

[t]he development of a credible and transparent carbon offset market and straightforward carbon offset marketing will assist Australia to reach its climate change goals. However, false or deceptive claims damage consumer perception of carbon offsetting, thereby damaging the emerging industry. ${ }^{15}$

\section{THE COST OF DECARBonisation: EUROPEAN EXPERIENCE}

Much debate has occurred since the release in March 2009 of the CPRS Bill. The debate has focused particularly on the cost to carbon emitters of the introduction of an ETS. Issues of cost are obviously of great interest not only to Australian emitters, but also to emitters elsewhere. It is reported that the current wholesale cost of UK electricity is around GB£32 billion, and it is calculated that every ton of $\mathrm{CO}^{2}$ emitted in electricity production will cost GB£35, with UK electricity suppliers paying an additional GB£8 billion for carbon permits. This is calculated to add 25 per cent to the total annual cost of electricity in that country. ${ }^{16}$

The UK Government recently detailed its plans to reduce carbon emissions by 34 per cent from 1990 levels by 2020. It also proposed to increase the amount of electricity generated from renewable sources so that, in 2020, it is estimated that 40 per cent will be obtained from wind and tidal energy as well as continuing nuclear power generation and 'clean coal' generation.

The EU Environment Committee has decided that approval of new rules will be sought from the European Parliament and the EU Member States, requiring coal powered electricity generators to meet the cost of 'all their carbon dioxide emissions from 2013'. ${ }^{18}$ The Committee also decided on 7 October 2008 that all large power stations constructed from 2015 are to be equipped

\footnotetext{
${ }^{15}$ Australian Competition and Consumer Commission, Carbon Claims and the Trade Practices Act (2008), 2.

${ }^{16}$ Christopher Booker, 'Financial Crisis: Lehman Misses Out on Carbon Credit Scam', The Sunday Telegraph (UK) (21 September 2008), 28.

17 'Britain outlines major carbon cuts', The Age (Melbourne), (17 July 2009), 11.

18 'EU Law Makes Power Firms Pay for All Emissions', The Australian (Sydney) (9 October 2008), 8.
} 
with carbon capture and storage technology (CCS), to prevent them releasing carbon dioxide into the atmosphere. ${ }^{19}$

\section{A Debate Yet to Occur}

It is surprising that there has been so little debate on whether an ETS system or a carbon tax regime would offer the better pathway to decarbonisation for Australia. It is not widely understood that ETSs such as that proposed in the 2009 CPRS Bill actually operate in a somewhat similar manner to carbon tax schemes, through limiting annual allowable emissions and hence increasing the cost of goods and services which are emissions-intensive. The difference between the two methods is that, with an ETS, the quantity of permitted emissions is controlled by the cap, while a carbon tax determines the price of emissions, with the marketplace deciding on the quantum of emissions that are economically possible.

\section{The Global Financial Crisis Makes Both Systems Problematic}

However the global financial crisis (GFC) has caused the overall price of carbon traded to drop significantly. In the first weeks of October 2008, the price of carbon dropped from US\$30 per tonne to below US\$22 per tonne. Given that the price in July 2008 had been as high as US\$37 per tonne, the necessary market stability for a carbon tax scheme currently seems problematic. $^{20}$ The impact of the GFC has confounded any reliance on more recent carbon prices.

Similarly, the Australian ETS proposed in the 2009 Bill would rely on the increasing scarcity of Australian Emission Units; their tradable value is of critical importance for the success of the scheme. The collapse in the worth of carbon tonnes and the resultant impact upon international emissions-trading is of concern, but is not unexpected. Martijn Wilder, Chair of the Sydney Carbon Market Taskforce observed in December 2008 that:

\footnotetext{
${ }^{19}$ European Parliament Press Release, 'Equipping power plants to store $\mathrm{CO}^{2}$ underground', 7 October 2008.

${ }^{20}$ Patrick Bond, 'Climate Justice False Solutions: A Timely Death?' (2009) $419 \mathrm{NeW}$ Internationalist 14.
} 
[a] good emissions trading scheme needs broad coverage and a carbon price sufficient to drive change. ${ }^{21}$

The prospects for the success of an ETS in Australia are yet to be determined, especially given that both emissions trading and carbon taxation are blunt tools attempting to offset GHG emitting economic activity against environmental protection (decarbonisation).

Perhaps, on balance, ETSs such as that contained in the CPRS Bill are preferable as they are more in harmony with international trends. Gittins observes that:

One good reason for preferring a trading scheme is that it fits better with what other countries are doing and allows international trading in permits. Where other countries can reduce their emissions more cheaply than we can, we effectively pay them to do it for us. ${ }^{22}$

The unanswered question remains, however, whether international preferences for an ETS over carbon trading suit the Australian milieu.

${ }^{21}$ Martijn Wilder, cited in 'Balancing Act on the Carbon Tightrope', The Sydney Morning Herald (Sydney) (13 December 2008), 22.

${ }^{22}$ Gittins, above n 2. 